\title{
Vertical air motions derived from a descending radiosonde using a lightweight hard ball as the parachute
}

\author{
H. Chen, Y. Zhu, J. Zhang, and Y. Xuan \\ Key Laboratory of the Middle Atmosphere and Global Environmental Observation, \\ Institute of Atmospheric Physics, Chinese Academy of Sciences, Beijing, 100029, China \\ Received: 30 April 2013 - Accepted: 28 August 2013 - Published: 4 September 2013 \\ Correspondence to: H. Chen (chb@mail.iap.ac.cn) \\ Published by Copernicus Publications on behalf of the European Geosciences Union.
}

\begin{abstract}
Knowledge of vertical air motions in the atmosphere is important for meteorological and climate studies due to its impact on clouds, precipitation and the vertical transport of air masses, heat, momentum, and composition. It is among the most difficult 5 quantities to measure because of its small magnitude. In this study, a descending radiosonde technique has been developed to detect the vertical wind speed (VW) in the atmosphere. The system is composed of a radiosonde and a $0.5-\mathrm{m}$ diameter hard ball made of plastic foam that acts as a parachute. The radiosonde hangs under the hard ball by a string which is then cut when the instrument is elevated into the upper tro10 posphere by a balloon. The VW is derived from the difference between the observed radiosonde descent rate and the calculated radiosonde descent rate in still air based on fluid dynamics. Deduction of the appropriate drag coefficient for the radiosonde is facilitated by the symmetrical shape of the parachute. An intensive radiosonde launch experiment was held in northern China during the summer seasons of 2010 to 2012.

15 This study uses radiosonde data collected during the campaign to retrieve the vertical air velocity within the radiosonde altitude-detecting range. In general, the VW ranges from -1 to $1 \mathrm{~m} \mathrm{~s}^{-1}$. Strong vertical air motion $\left(\sim 2 \mathrm{~m} \mathrm{~s}^{-1}\right)$ is seen in a few radiosonde measurements. Although considerable uncertainties exist in measuring weak vertical air motions, a case study shows that there is reasonable agreement between retrievals of $\mathrm{VW}$ in the lower atmosphere from the radiosonde and a wind profiler radar located at the launch site.
\end{abstract}

\section{Introduction}

Vertical air motion reflects dynamic processes in the atmosphere and is crucial to cloud diagnostics and numerical simulation validations (Heymsfield, 1977), as well as investigations into the aerosol indirect effect on climate change (Gong et al., 2007). Vertical motion determines the locations of activated cloud droplets that originate at the 
cloud top and base, so can affect cloud formation (Paluch and Lenschow, 1991; Sun et al., 2012). Vertical air motions associated with anvil clouds play a significant role in the mass and heat budgets of intense tropical convection systems (Leary and Houze, 1980). By conducting an overview of the parameterization of gravity wave drag in nu5 merical weather prediction and climate simulation models, Kim et al. (2003) demonstrated a close relationship between the vertical velocity and the propagation, evolution and dissipation of gravity waves.

Knowledge of vertical air motions in the atmosphere is important for meteorological and climate studies because of their impact on clouds, precipitation and gravity waves.

10 It is crucial to obtain the vertical wind speed (VW) on all temporal and spatial scales. Unfortunately, the vertical air velocity is among the most difficult quantities to measure due to its small magnitude (Holton, 1992). Even in the case of moderate and strong convection, this parameter with a magnitude greater than a few meters per second is not easy to measure because of its random occurrence. At present, profiles of hori-

15 zontal and vertical wind speeds can be simultaneously and remotely measured using a ground-based Doppler wind profiler (Balsley et al., 1988), a vertical pointing cloud radar (Shupe et al., 2008), a sodar or a lidar (Contini et al., 2004). Airborne instruments can provide some in-situ measurements of three-dimensional wind components, as well as turbulence parameters. Nevertheless, the in-situ direct observations of wind informa20 tion are still very sparse.

Although progress has been made in recent years with these detecting approaches, additional observations are sorely needed. It is thus necessary to develop a new system to directly measure both horizontal and vertical wind speeds. Widely available radiosonde data have been generally used to obtain information about the state of the atmosphere. Moreover, the balloon ascent rate and the radiosonde descent rate, calculated from global positioning system altitude data, can reflect the nature of air motion. Many studies on investigating atmospheric waves have been conducted using the derived radiosonde ascent rate (e.g. Lalas and Einaudi, 1980; McHugh et al., 2008). By analyzing the ascent rate of a radiosonde balloon, Johansson and Bergström (2005)

8109

showed that the vertical velocity of the balloon could be used to determine the height of the boundary layer because a decrease in ascending velocity appeared as a jump at the top of the boundary layer. Their study also suggested that the balloon ascent was potentially a good indirect measure of turbulence. MacCready (1965) showed that 5 a rising spherical balloon exhibited self-induced lateral motions and that a radiosonde had the pendulum effect, which could introduce errors in wind retrievals. However, the dropsonde descent rate is much smoother than the radiosonde ascent rate. The vertical wind velocity derived from dropsonde profiles have been used to study hurricane structure (e.g. Franklin et al., 2003; Wu et al., 2007). By analyzing radiosonde and drop10 sonde data collected during the Terrain-induced Rotor Experiment (T-REX) over Owens Valley, California, from March to April 2006, Wang et al. (2009) validated the technique for using sonde-based data to derive the vertical velocity of air from the surface to the stratosphere. Vertical velocities obtained from radiosonde and dropsonde profiles were also compared to those derived from aircraft and the profiling radar located at the site.

15 Their study demonstrated that the sonde-estimated vertical velocity was able to capture and describe events with strong vertical motions (greater than $1 \mathrm{~m} \mathrm{~s}^{-1}$ ) observed during T-REX. They also showed that radiosonde data overestimated vertical velocities below $5 \mathrm{~km}$ a.g.l. (above ground level).

A descending radiosonde system based on Wang et al. (2009) and validation of 20 WV retrievals from this system is presented here. Validation is performed using data collected during a field experiment held in northern China during the summer seasons of 2010 to 2012. Section 2 describes the instrumentation and measurements used in this study. Analyses of the VW derived using the descending radiosonde technique is presented in Sect. 3. Main conclusions are summarized in Sect. 4.

\section{Instrumentation and measurements}

Figure 1 shows a schematic diagram of the descending radiosonde detection system. It is composed of a radiosonde and a $0.5-\mathrm{m}$ diameter hard ball made of plastic foam 
that acts as the parachute. The conventional parachute used for the radiosonde is generally made of the soft materials. The area of thrust surface will vary during the descent period due to the deformation and swing of the parachute. The hard light ball presented in our system does not deform during the ascent and descent periods. The symmet-

5 rical shape of the ball guarantees a constant cross-section. So, the drag forces or the drag coefficient can be calculated with less uncertainty. Based on this, the vertical air motions can be better retrieved in comparison with those from dropsondes with soft parachute. A cutter triggered by a timer is placed above the hard ball. The radiosonde hangs under the hard ball using a string of $40 \mathrm{~m}$ in length which is cut when the in-

10 strument package is elevated to the upper troposphere by a balloon. The radiosonde deployed in the study is provided by the Changfeng Company which participated in the Eighth World Meteorological Organization International Radiosonde Comparison in Yangjiang in 2010 (Nash et al., 2011; Li and Li, 2011). The measurements are the temperature, relative humidity, pressure, wind speed, and wind direction. No orienta-

15 tion control is deployed in the system. So the radiosonde can rotate freely during the launches. The radiosonde sensor is oriented and positioned during the descent as same as during the ascent, i.e. the temperature and relative humidity sensors reaching out from upper part of one lateral side of radiosonde box. The hard ball can decrease the radiosonde descent to obtain more accurate measurements by reducing the time

20 lag errors. Meanwhile, the slow radiosonde descent can also help to derive more accurate VW by good retrievals of air density and drag coefficient. Up to eight radiosonde profiles from different radiosondes can be recorded simultaneously and continuously by a multi-channel receiver. The radiosonde ascent rate is $\sim 5 \mathrm{~m} \mathrm{~s}^{-1}$. It generally takes about $45 \mathrm{~min}$ for the radiosonde to travel through the troposphere, so the time for the cutter trigger is set to $45 \mathrm{~min}$.

The descent rate, $W_{d}$, of the radiosonde system in still air can be calculated using the following formula, based on the balance between gravity and drag forces (Johansson and Bergström, 2005):

$m_{\mathrm{s}} g=C_{\mathrm{d}} A_{\mathrm{b}} \rho W_{\mathrm{d}}^{2} / 2$,

where $m_{\mathrm{s}}$ is the total mass of the radiosonde and hard ball (in $\mathrm{kg}$ ), $C_{\mathrm{d}}$ is the drag coefficient, $A_{\mathrm{b}}$ is the cross-sectional area of the hard ball (in $\mathrm{m}^{2}$ ) (the area of radiosonde box is ignored due to its small part), and $\rho$ is the air density (in $\mathrm{kg} \mathrm{m}^{-3}$ ), which can be calculated from temperature and pressure profiles. The descent rate is in $\mathrm{ms}^{-1}$.

5 Deduction of the appropriate drag coefficient $\left(C_{\mathrm{d}}\right)$ for the radiosonde is facilitated by the symmetrical shape of the parachute.

The VW is calculated as the difference between the observed radiosonde descent rate and that calculated in still air (Wang et al., 2009). More than 50 radiosondes were released during the summer seasons of 2010 to 2012 under convective and 10 non-convective conditions in northern China. The experiment was carried out at three sites: Changchun $\left(44.19^{\circ} \mathrm{N}, 125.02^{\circ} \mathrm{E}, 175 \mathrm{~m}\right.$ a.s.l. - above sea level), Lhasa $\left(29.66^{\circ} \mathrm{N}\right.$, $91.14^{\circ} \mathrm{E}, 3650 \mathrm{~m}$ a.s.I.) and Baochang $\left(41.41^{\circ} \mathrm{N}, 115.14^{\circ} \mathrm{E}, 1380 \mathrm{~m}\right.$ a.s.I.). The vertical air velocity retrieval technique was developed using profiles collected during the summer of 2012 over the Baochang site. A boundary layer wind profiling radar was de-

15 ployed during the Changchun campaign of 2010 for a short period due to the restrained conditions. This radar can provide vertical air motion profiles at a temporal resolution of 5 minutes from the surface upwards to $\sim 4.5 \mathrm{~km}$ a.g.l. A comparison was conducted between radiosonde retrievals and wind profiling radar measurements at the Changchun site.

\section{Results}

Twenty-one radiosondes were released over Baochang during the summer of 2012. Figure 2 shows various profiles from one radiosonde launch made on 4 August 2012 at 11:09 LST (local standard time). Figure 2a-d present temperature, relative humidity $(\mathrm{RH})$, horizontal wind speed, and horizontal wind direction profiles during ascending and descending periods, respectively. Figure $2 e$ and f show the radiosonde ascent velocity and the radiosonde descent velocity. Temperature and wind speed/direction profiles during ascent and descent are in reasonable agreement. A wetter $\mathrm{RH}$ profile is ob- 
served during the descending period than during the ascending period, which might be supposed that the observational environment changes because of the radiosonde shift associated with the horizontal wind. The radiosonde ascent velocity (Fig. 2e) generally ranges from 5 to $6.5 \mathrm{~m} \mathrm{~s}^{-1}$. As the altitude decreases from $13.5 \mathrm{~km}$ to $0.4 \mathrm{~km}$ a.g.l., the 5 radiosonde descent velocity (Fig. 2 f) decreases from $\sim 30$ to $\sim 15 \mathrm{~m} \mathrm{~s}^{-1}$.

Figure 3 shows the maximum and minimum altitudes reached during the 21 radiosonde launch events. Maximum heights attained are greater than $10 \mathrm{~km}$, after which the radiosonde begins to descend. The minimum altitude recorded hovers around $0.5 \mathrm{~km}$ because the receiver misses the data signal below that level due to blocking

10 by the terrain. Profile data obtained under stable weather conditions and with smooth descent speeds are chosen to assume the radiosonde descent rate in still air (Fig. 4). In general, the radiosonde descent speed in quasi-still air ranges from $\sim 27 \mathrm{~m} \mathrm{~s}^{-1}$ at $12 \mathrm{~km}$ to $\sim 15 \mathrm{~m} \mathrm{~s}^{-1}$ at $500 \mathrm{~m}$ above the surface. Below $10 \mathrm{~km}$ a.g.l., the standard deviation is less than $0.4 \mathrm{~m} \mathrm{~s}^{-1}$.

15 Figure 5 presents the vertical distributions of calculated air density and drag coefficient over the Baochang site. The air density decreases from $1 \mathrm{~kg} \mathrm{~m}^{-3}$ at the surface upwards to $0.3 \mathrm{~kg} \mathrm{~m}^{-3}$ at $12 \mathrm{~km}$. The drag coefficient varies little $(0.32-0.33)$. In a manner similar to the standard deviation of the radiosonde descent rate (shaded area in Fig. 4), the standard deviation of the drag coefficient is larger near the surface and in 20 the upper troposphere than in the middle troposphere.

Vertical distributions of air density derived from each radiosonde launch and drag coefficient were then used in Eq. (1) to calculate $W_{d}$ in still air for that sounding. Figure 6 shows vertical distributions of the observed radiosonde descent rate and the vertical wind speed retrieved from all radiosonde descents. In general, the observed 25 radiosonde descent rate varies from $\sim 26 \mathrm{~m} \mathrm{~s}^{-1}$ at $10 \mathrm{~km}$ to $\sim 14 \mathrm{~m} \mathrm{~s}^{-1}$ in the boundary layer. Most vertical wind speeds range from -1 to $1 \mathrm{~m} \mathrm{~s}^{-1}$. Strong vertical air speeds with magnitudes close to $2 \mathrm{~m} \mathrm{~s}^{-1}$ are seen in a few radiosonde profiles, such as radiosonde launch numbers 7 and 19. To more clearly see vertical variations in wind speed, retrieval results derived from six radiosonde profiles (numbers $3,12,13,16$,

8113

17, and 19) were selected and are shown in Fig. 7. Black, blue, and red lines represent the observed radiosonde descent rate, the calculated radiosonde descent rate, and the vertical wind speed, respectively. In general, vertical wind speeds are small and stable in half of the profiles (Fig. 7b, c, and e). Air speeds in the downward direction greater 5 than $2 \mathrm{~m} \mathrm{~s}^{-1}$ are observed in profile number 3 at mid-levels of the troposphere (Fig. 7a). Large upward air speeds are observed in the lower troposphere in profile numbers 16 and 19 (Fig. 7d and f). Vertical air speeds greater than $1 \mathrm{~m} \mathrm{~s}^{-1}$ are clearly evident in these particular cases.

The time taken for a radiosonde to travel through a certain distance can partly reflect 10 the magnitude of the vertical air motion. Figure 8 shows the time taken for radiosondes to descend from 9 to $3 \mathrm{~km}$ a.g.l. Figures 8 and $6 \mathrm{~b}$ show that the case where the radiosonde takes the longest time to descend (launch number 7 ) corresponds to when the upward wind speed is greatest. The quickest radiosonde descents (launch numbers $1,9,14,18$, and 21) occur when there is apparent downward air motion.

15 Figure 9 shows an example of measurements and retrievals obtained at the Changchun site where a wind profiling radar was deployed. The radar used in the field campaigns is provided by Airda Electronics Company and operated at $1290 \mathrm{MHz}$. Its measurement height ranges normally from 50 to $3000 \mathrm{~m}$ a.g.l. with a vertical resolution of $50 \mathrm{~m}$. Under favorable conditions, the radar observation ceiling height can frequently

20 reach up to $\sim 6000 \mathrm{~m}$, sometimes with observation gap above $3000 \mathrm{~m}$. The measurement accuracy is estimated to be $1.5 \mathrm{~m} \mathrm{~s}^{-1}$ for wind speed and $10^{\circ}$ for wind direction. It is believed that vertical wind can be measured with better accuracy by a boundary wind profiler because it is a direct measurement from the zenith-directed beams without horizontal homogeneity problem. However, due to its small mean magnitude and

25 high variability of the vertical wind and because of descent radiosonde drift from the launching site, it's difficult to obtain point-to-point data of the vertical wind measurements for comparison. Here, we only show an example of vertical wind measurements by a boundary layer wind profiler and the descent radiosonde. The radiosonde was released on 31 May 2010 at 09:55 LST. Vertical profiles of temperature and RH recorded 
by the radiosonde are shown in Fig. 9a and b, respectively. Vertical air velocities obtained from the descent radiosonde retrieval and wind profiling radar observations are shown in Fig. 9c. Despite some considerable uncertainties that arise when vertical air motion is weak, the general agreement between radiosonde retrievals and wind profiler

5 measurements of air vertical velocity is reasonable. Other reason to select this case is that one thick layer between 6 to $10 \mathrm{~km}$ with upward air motion larger than $1 \mathrm{~m} \mathrm{~s}^{-1}$ and one layer around $11 \mathrm{~km}$ with very strong downward air motion can be observed.

\section{Conclusions}

Knowledge of vertical air motions in the atmosphere is important for meteorological 10 and climate studies because of their impact on clouds and gravity waves. It is among the most difficult quantities to measure due to its small magnitude. Some progress in measuring wind speeds within the troposphere has been made in recent years using instruments such as the ground-based Doppler wind profiler, the vertical pointing cloud radar, and the sodar and lidar. However, additional observations are sorely needed.

15 It is thus necessary to develop a new system to directly measure both horizontal and vertical wind speeds.

The balloon ascent rate and the radiosonde descent rate can characterize air motion. Wang et al. (2009) proposed a technique for using dropsonde data to derive the vertical velocity of air from the surface to the stratosphere. Based on their study, we developed

20 a descending radiosonde system. It is composed of a radiosonde and a $0.5-\mathrm{m}$ diameter hard ball made of plastic foam that acts as a parachute. The radiosonde hangs under the hard ball by a string which is then cut when the instrument is elevated into the upper troposphere by a balloon. The vertical wind speed is derived from the difference between the observed radiosonde descent rate and the calculated radiosonde descent rate in still air based on fluid dynamics. Deduction of an accurate drag coefficient for the radiosonde is facilitated by the symmetrical shape of light hard ball.

$$
8115
$$

An intensive radiosonde launch experiment was held in northern China during the summer seasons of 2010 to 2012 . By using radiosonde data collected during the campaign, the vertical air velocity was derived within the radiosonde altitude-detecting range. Retrievals show that reasonable estimates of vertical air motion can be de5 rived using the technique presented in this study. In general, the vertical wind speed varies from -1 to $1 \mathrm{~m} \mathrm{~s}^{-1}$ Strong vertical air motion $\left(\sim 2 \mathrm{~m} \mathrm{~s}^{-1}\right)$ is seen in a few radiosonde measurements. Despite some considerable uncertainties that arise when the vertical air motion is weak, the general agreement between radiosonde retrievals and wind profiler measurements of air vertical velocity in the lower atmosphere during a 10 case study is reasonable. The validations of the radiosonde-based vertical air motion retrieval method are not conducted comprehensively in this study due to the lack of collocated observations. As the next step, we will choose the site with better conditions to conduct the joint experiment of radiosonde and tropospheric wind profiler radar to carry out the full validations.

15 Acknowledgements. The authors would like to thank Yu Zhao, Xiaoping Zhang, Jun Li, and Chao Ling for preparing and launching the radiosondes. Special thanks to Maureen Cribb from University of Maryland for editing the English. This work is supported by the NSF of China under Grant No. 40975001 and No. 41275039 and by the Ministry of Science and Technology of China (2010CB950804).

20 References

Balsley, B. B., Ecklund, W. L., Carter, D. A., Riddle, A. C., and Gage, K. S.: Average vertical motions in the tropical atmosphere observed by a radar wind profiler on Pohnpei $\left(7^{\circ} \mathrm{N}\right.$ latitude, $157^{\circ}$ E longitude), J. Atmos. Sci., 45, 396-405, 1988.

Contini, D., Mastrantonio, G., Viola, A., and Argentini, S.: Mean vertical motions in the PBL measured by Doppler sodar: Accuracy, ambiguities, and possible improvements, J. Atmos. Ocean. Tech., 21, 1532-1544, 2004.

Franklin, J., Black, M. L., and Valde, K.: GPS dropwindsonde wind profiles in hurricanes and their operational implications, Weather Forecast., 18, 32-44, 2003. 
Gong, D. Y., Ho, C. H., Chen, D., Qian, Y., Choi, Y. S., and Kim, J.: Weekly cycle of aerosol-meteorology interaction over China, J. Geophys. Res., 112, D22202, doi:10.1029/2007JD008888, 2007.

Heymsfield, A. J.: Precipitation Development in Stratiform Ice Clouds: A Microphysical and

5 Dynamical Study, J. Atmos. Sci., 34, 367-381, 1977.

Holton, J. R.: An Introduction to Dynamic Meteorology, Academic Press, San Diego, 507 pp., 1992.

Johansson, C. and Bergström, $\mathrm{H}$.: An auxiliary tool to determine the height of the boundary layer, Bound.-Lay. Meteorol., 115, 423-432, 2005.

$10 \mathrm{Kim}$, Y. J., Eckermann, S. D., and Chun, H. Y.: An overview of the past, present and future of gravity-wave drag parameterization for numerical climate and weather prediction models, Atmos.-Ocean, 41, 65-98, 2003

Lalas, D. P. and Einaudi, F.: Tropospheric gravity waves: Their diction by and influence on rawinsonde balloon data, Q. J. Roy. Meteorol. Soc., 106, 855-864, 1980.

15 Leary, C. A. and Houze, R. A.: The Contribution of Mesoscale Motions to the Mass and Heat Fluxes of an Intense Tropical Convective System, J. Atmos. Sci., 37, 784-796, 1980.

$\mathrm{Li}, \mathrm{B}$. and Li, W.: A Review of Yangjiang 8th International Radiosonde Intercomparison, Adv. Meteorol. Sci. Tech., 1, 6-13, 2011.

MacCready, P. B.: Comparison of some balloon techniques, J. Appl. Meteorol., 4, 504-508, 201965.

McHugh, J. P., Dors, I., Jumper, G. Y., Roadcap, J. R., Murphy, E. A., and Hahn, D. C.: Large variations in balloon ascent rate over Hawaii, J. Geophys. Res., 113, D15123, doi:10.1029/2007JD009458, 2008.

Nash, J., Oakley, T., Vömel, H., and Li, W.: WMO intercomparison of high quality radiosonde 25 systems Yangjiang, China, 12 July-3 August 2010, WMO/TD-No. 1580, WMO, Geneva, 2011.

Paluch, I. R. and Lenschow, D. H.: Stratiformcloud formation in the marine boundary layer, J. Atmos. Sci., 48, 2141-2158, 1991.

Shupe, M. D., Kollias, P., Poellot, M., and Eloranta, E.: On deriving vertical air motions from cloud radar Doppler spectra, J. Atmos. Ocean. Tech., 25, 547-557, 2008.

Sun, J., Leighton, H., Yau, M. K., and Ariya, P.: Numerical evidence for cloud droplet nucleation at the cloud-environment interface, Atmos. Chem. Phys., 12, 12155-12164, doi:10.5194/acp12-12155-2012, 2012.

8117

Wang, J. H., Bian, J. C., Brown, W. O., Cole, H., Grubišić, V., and Young, K.: Vertical Air Motion from T-REX Radiosonde and Dropsonde Data, J. Atmos. Ocean. Tech., 26, 928-942, 2009.

Wu, C. C., Chou, K. H., Lin, P. H., Aberson, S. D., Peng, M. S., and Nakazawa, T.: The impact of dropwindsonde data on typhoon track forecasts in DOTSTAR, Weather Forecast., 22, 1157$5 \quad 1176,2007$. 
Hellium

Balloon
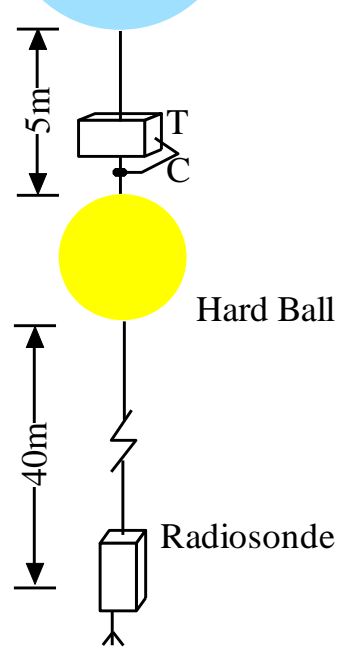

Fig. 1. Schematic (not to scale) of the radiosonde package in ascent. A hard plastic foam ball with a diameter of $0.5 \mathrm{~m}$ replaces the parachute in the normal radiosonde package. $T$ and $C$ denote the timer and cutter.
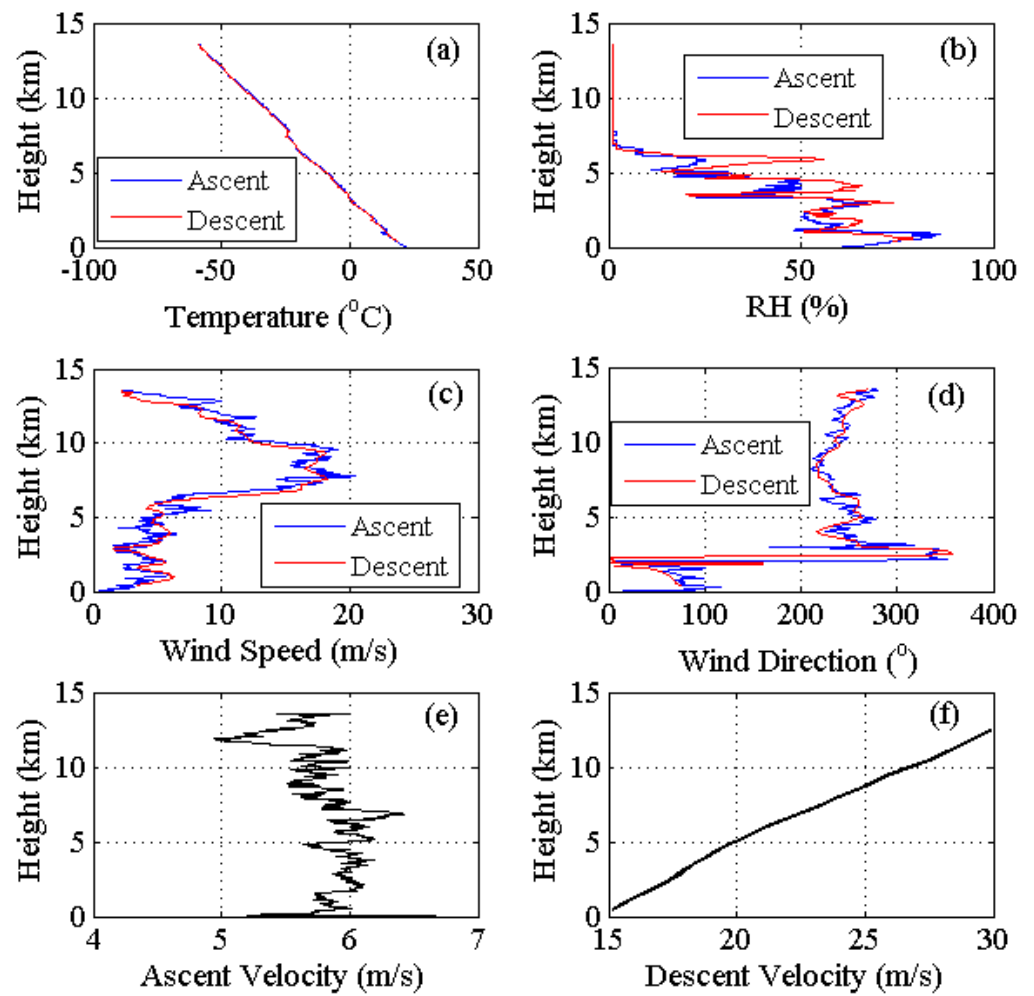

Fig. 2. Profiles of (a) temperature, (b) relative humidity, (c) horizontal wind speed, (d) horizontal wind direction, (e) radiosonde ascent velocity and (f) radiosonde descent velocity. Blue and red lines in (a)-(d) represent ascent and descent, respectively. 


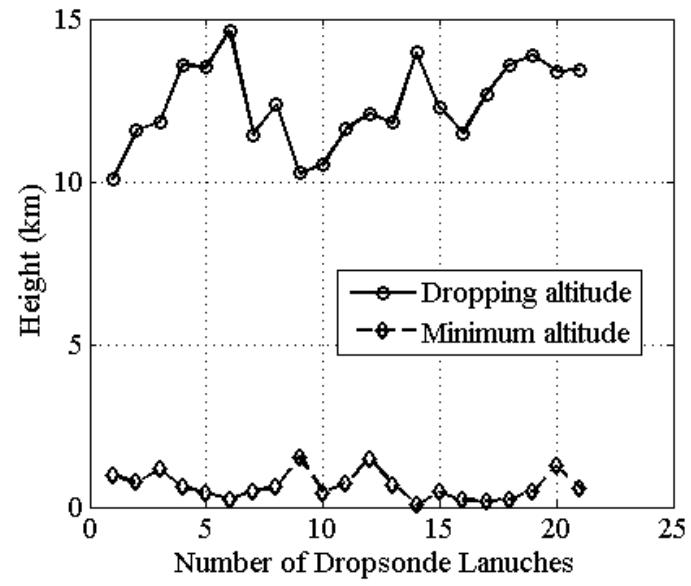

Fig. 3. Altitudes at which radiosondes start to drop (circles) and the lowest altitudes detected (diamond). Heights are measured above ground level.

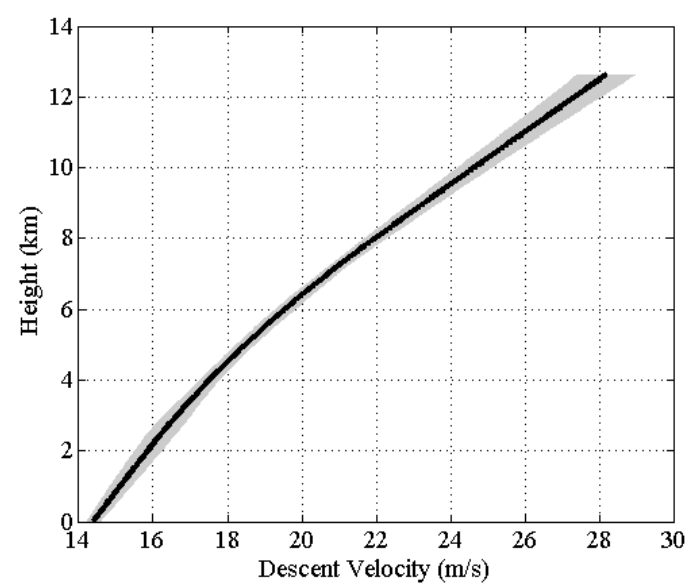

Fig. 4. Retrieved radiosonde descent rate in still air (black line). Shaded grey areas represent the standard deviation. 

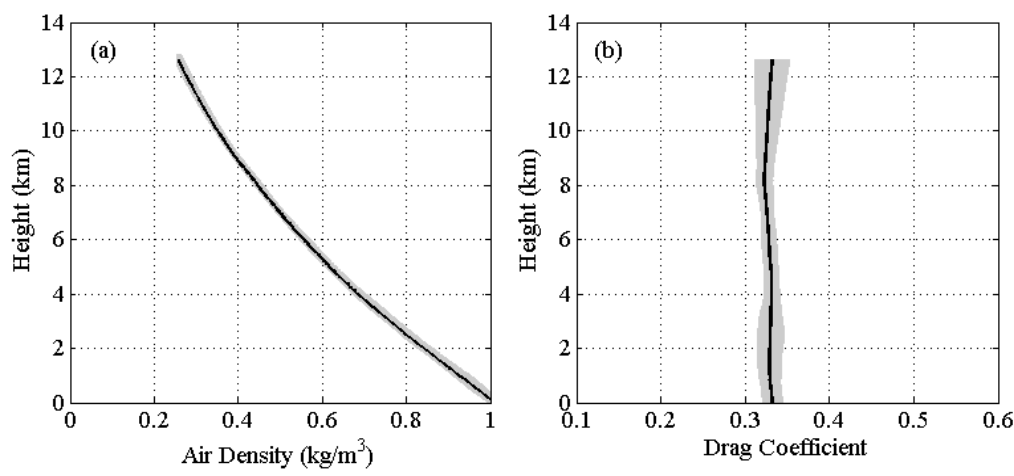

Fig. 5. Vertical profiles of (a) air density and (b) drag coefficient over the Baochang site. Shaded grey areas represent the standard deviation.
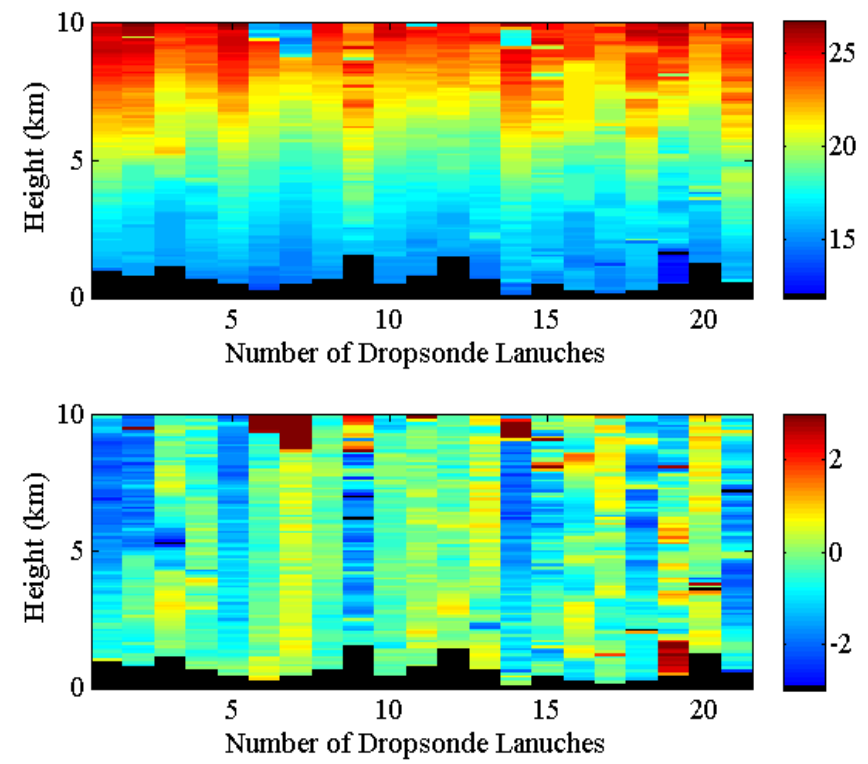

Fig. 6. Vertical distributions of (a) the observed radiosonde descent rate and (b) the retrieved vertical wind speed for all radiosonde launches. Black areas denote missing data due to the loss of the radiosonde signal. 


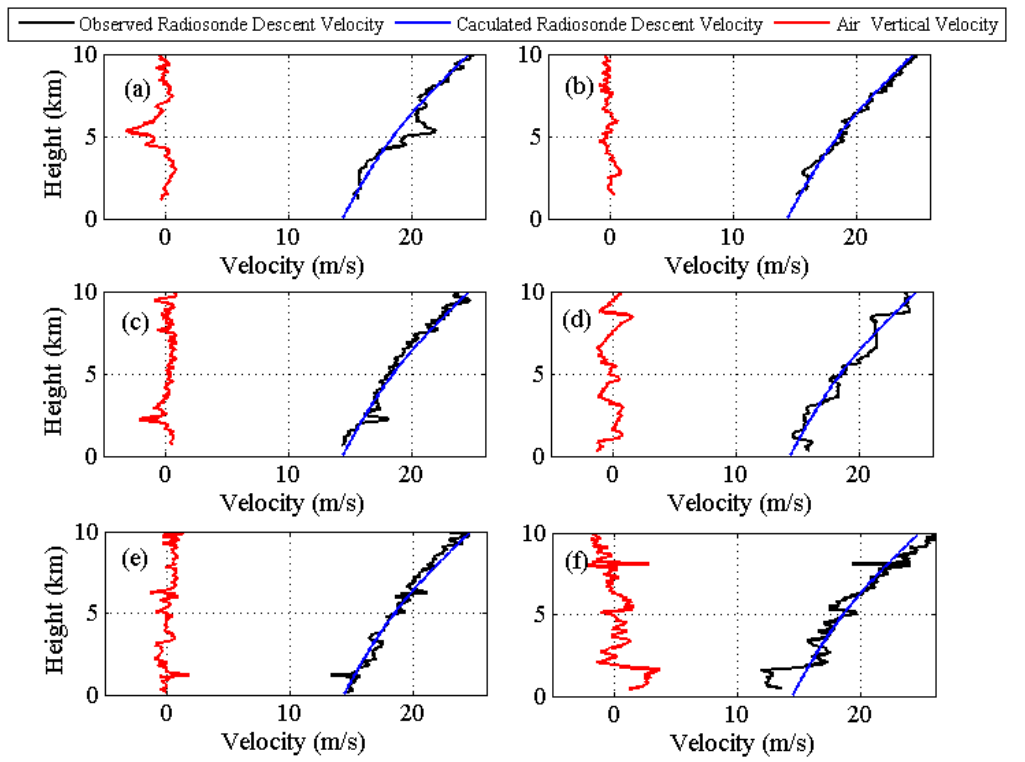

Fig. 7. Vertical profiles of the observed radiosonde descent velocity (black lines), the calculated radiosonde descent velocity (blue lines), and the air velocity (red lines). Six cases are shown.

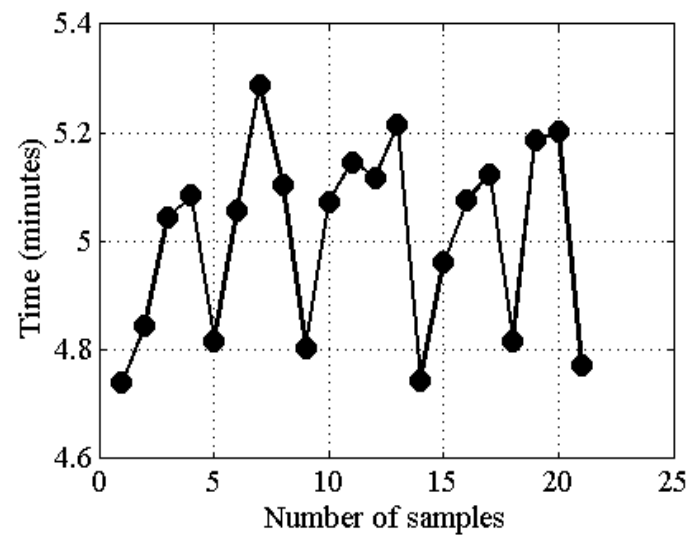

Fig. 8. Time taken by radiosondes to descend from 9 to $3 \mathrm{~km}$ above ground level. 

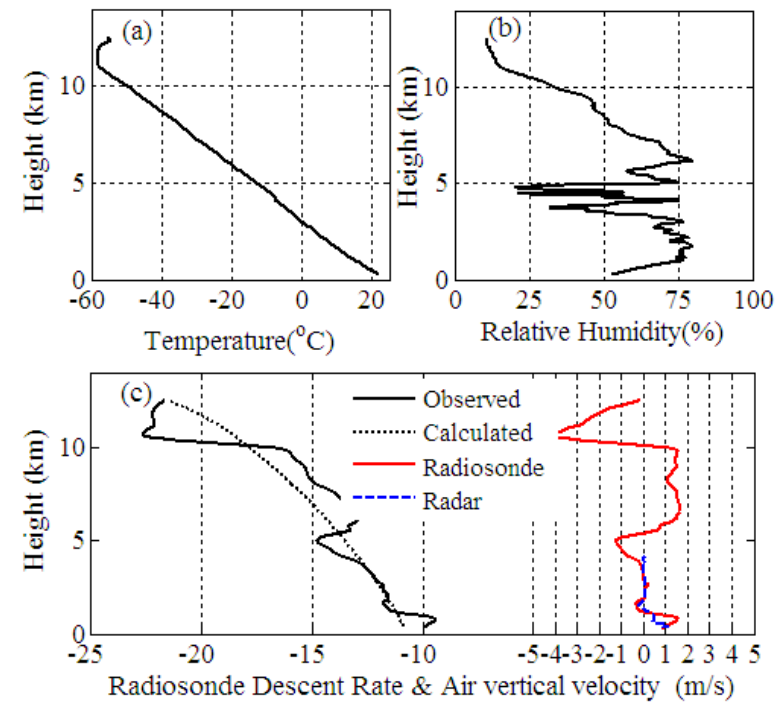

Fig. 9. Vertical profiles of (a) temperature, (b) relative humidity, and (c) radiosonde descent speed, as well air vertical velocity, derived from a sounding made in Changchun on 31 May 2010. The black solid line, black dashed line, red line, and blue line in (c) represent the observed radiosonde descent velocity, the calculated radiosonde descent velocity, the vertical wind velocity derived from the radiosonde, and the vertical wind velocity observed by the wind profiler radar, respectively. 